\title{
Pharmacokinetics of a new imidazoline receptor agonist in rat plasma after intragastric and intravenous administration
}

\author{
Kulikov Aleksandr", Avtina Tatyana, Pokrovsky Mikhail, Korokin Mikhail \\ Department of Pharmacology, Belgorod State National Research University, 85 Pobedy St., Belgorod, 308015, Russia .
}

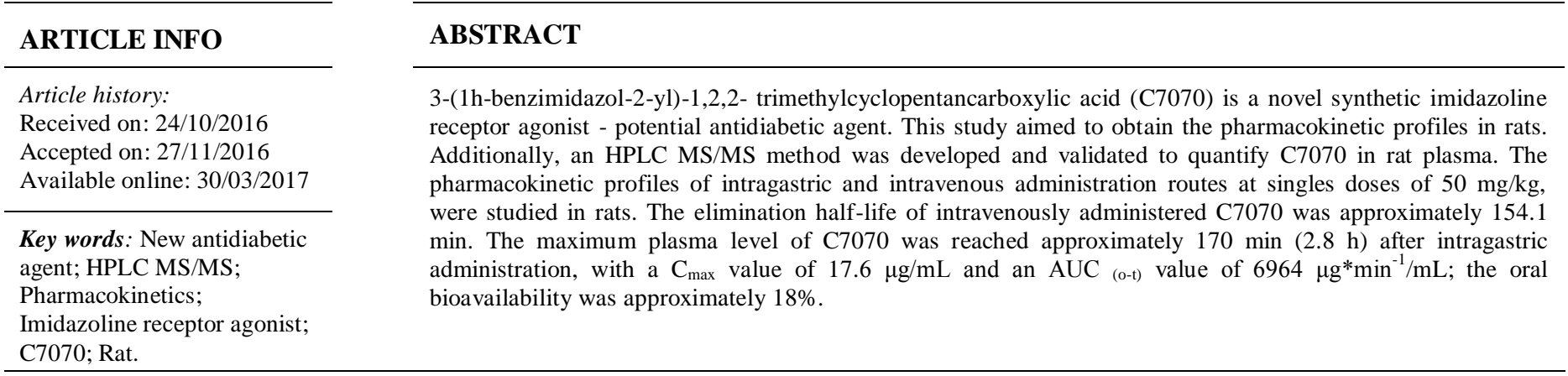

\section{INTRODUCTION}

High blood pressure, or hypertension, is a condition that often affects people with type 2 diabetes. It is widely assumed that obesity, a high-fat, high-sodium diet, and inactivity have led to a rise in both conditions. Type 2 diabetes is a major cause of morbidity and an important risk factor for cardiovascular disease, cerebral infarction, blindness, and kidney failure. The prevalence of type 2 diabetes is increasing worldwide, and it is estimated that more than 366 million people will be affected by 2030 (Brigand et al., 1997). Pharmacologic treatment of many type 2 diabetic patients requires separate agents for treating hyperglycemia, and hypertension. This results in patients having to take multiple medications, which negatively impact patient compliance and increases the risk for drug interaction. In response to this growing health care problem, compounds the at have the ability to counter both hyperglycemia and hypertension would positively impact compliance and be an asset to patients

* Corresponding Author

Email: kulikov@bsu.edu.ru
(Mourtada et al., 1998). At present, to solve such problems is to use a prospective direction imidazoline receptor agonists (Brigand et al., 1999).

Pharmacologic criteria have defined three main types of imidazoline receptors: the $\mathrm{I}_{1}$ subtype is labeled by $\left[{ }^{3} \mathrm{H}\right]$ clonidine and the $I_{2}$ subtype is labeled by $\left[{ }^{3} \mathrm{H}\right]$ idazoxan. A third pharmacologically distinct entity, the $\mathrm{I}_{3}$ subtype, is found in the pancreas and is involved in regulation of insulin secretion. Several studies have shown that compounds containing the imidazoline moiety are potent stimulators of insulin secretion from pancreatic $\beta$ -cells [1-5]. Development and study of imidazoline receptor agonist is of great importance in the treatment of type 2 diabetes and hypertension. Preparation of the pharmacokinetic profiles for various routes of administration in animals is an important step in developing drugs (Efanov et al., 2001).

\section{MATERIALS AND METHODS}

\section{Chemicals, reagents and animals}

We used the following reagents: C7070 ("VladMiVa", RF, Belgorod), fabomotizole - IS (Sigma), formic acid (Panreac), ammonium acetate (Panreac), methanol (Merk), acetonitrile 
gradient grade (Merk), deionized water of system «Gene Pure» (Thermo Scientific, USA).

We used the rats Wistar. The animals were housed in the Center of preclinical and clinical studies support the cycle day/night, temperature of $25 \pm 2{ }^{\circ} \mathrm{C}$ and relative humidity $50 \pm 5 \%$. The rats were fasted overnight (approximately $12 \mathrm{~h}$ ) before each experiment. The basic rules of maintenance and care meet the standards, according to the guide: Guide for the care and use of laboratory animals (National Academy press. -Washington, D.C. 1996).

\section{Equipments}

- HPLC Thermo Ultimate 3000 (Thermo Scientific);

- MS/MS Velos Pro (Thermo Scientific);

- Pipettes 0.5-10 $\mu \mathrm{L}, 10-100 \mu \mathrm{L}, 20-200 \mu \mathrm{L}$ и $100-1000 \mu \mathrm{L}$ (Eppendorf);

- Soft Xcalibur 2.2 Sp1(Thermo Scientific);

- Ultrasonic bath;

- HPLC column Zorbax Eclipse XDB-C18 (3.5 $\mu \mathrm{m}, 150$ x 3.0 Mм + guard cartridge);

- Centrifuge (Thermo Scientific Micro CL 17R).

\section{Animal experiment \\ Experiment design}

To study the pharmacokinetics of 12 rats were precatheterized in the right jugular vein to sample blood at all-time points were taken from the same animal throughout the experiment. For the operation intraperitoneal anesthesia used: $10 \%$ zoletil $2 \%$ xylazine $=1: 5$, at $70 \mathrm{ul} / 100 \mathrm{~g}$ body weight. After the operation was monitored daily animal health. In the 12 hours before the start of the experiment the animals were deprived of food, leaving free access to water. On the third day of the study drug was administered after catheterization (Olsen et al., 2003).

For intravenous dosing, test substance is administered a bolus of 6 rats in the tail vein as a solution of $50 \mathrm{mg} / \mathrm{ml}$ in propylene glycol at $50 \mathrm{mg} / \mathrm{kg}$. Blood was collected through the catheter in a volume of $0.2 \mathrm{~mL}$ polypropylene tubes containing 20 ul of $5 \% \mathrm{~K} 3$ to enter, at 5, 15, 30, 60, 120, 240, 480, and 1440 minutes after administration.

When the substance was administered intragastrically dosed with a probe in a solution of $50.0 \mathrm{mg} / \mathrm{ml}$ in propylene glycol at $50 \mathrm{mg} / \mathrm{kg}$. Blood was collected through the catheter in a volume of $0.2 \mathrm{~mL}$ polypropylene tubes containing $20 \mathrm{ul}$ of $5 \% \mathrm{~K} 3$ to input $15,30,60,120,240,480$, and 1440 minutes after administration. Blood plasma was separated by centrifugation at $5600 \mathrm{~g}$ for $10 \mathrm{~min}$, and stored until analysis at a temperature of $70{ }^{\circ} \mathrm{C}$.

\section{Analytical method}

Plasma concentrations of C7070 were measured by an Thermo Ultimate 3000 (Thermo Scientific) HPLC system equipped with - MS/MS detector Velos Pro (Thermo Scientific). Separations were carried out on an Exlipse XDB C18 column (150 $\mathrm{mm} \times 3.0 \mathrm{~mm}, 3.5 \mu \mathrm{m})$ with a guard cartridge. The mobile phase consisted of $5 \mathrm{mM}$ ammonium acetate $+0,1 \%$ formic acid (A), methanol $(B)$, acetonitrile $(C)$ in gradient mode $(0 \rightarrow 5$ min: $\quad A$ $80 \%, \mathrm{~B}-0 \%, \mathrm{C}-20 \%$; $5.0 \rightarrow 8.5 \mathrm{~min}: \mathrm{A}-65 \%$, B - $10 \%$, C$10 \% ; 8.5 \rightarrow 9.0$ min: A - $20 \%, \mathrm{~B}-10 \%, \mathrm{C}-70 \%$; $9.0-11.0 \mathrm{~min}$ A $-20 \%, \mathrm{~B}-10 \%, \mathrm{C}-70 \% ; 11.0 \rightarrow 11,1 \mathrm{~min} \mathrm{~A}-80 \%, \mathrm{~B}-0 \%$, C$20 \% ; 11.1 \rightarrow 12.0 \mathrm{~min} \mathrm{~A}-80 \%, \mathrm{~B}-0 \%, \mathrm{C}-20 \%$ ) at a flow-rate of $0.4 \mathrm{~mL} / \mathrm{min}$. The parameters of the detector: ESI positive mode, conversion masses for $\mathrm{C} 7070272.35 \rightarrow 255.15$; for IS $307.41 \rightarrow 114.0$ source temperature $300{ }^{\circ} \mathrm{C}$, voltage at the source 3 $\mathrm{kV}$, remaining parameters in accordance with an automatic optimization tool. The temperature of the samples $-4.0{ }^{\circ} \mathrm{C}$, column $-40.0{ }^{\circ} \mathrm{C}$, injection volume $-2.0 \mu \mathrm{L}$. Before the research method has been validated [6-7]. Retention time C7070 - about $4.7 \mathrm{~min}$, IS - about $8.5 \mathrm{~min}$

\section{Concentration determination}

The concentration was determined from a linear standard curve ranging from $3.9 \mathrm{ng}$ to $20 \mathrm{mg}$ per/ml of plasma. For this purpose, standard solutions were prepared solutions and solutions QC. Preparation of the solutions included the following steps of: $100 \mathrm{ul}$ of plasma were placed in vials "eppendorf" $1.5 \mathrm{ml}$, was added $100 \mathrm{ul}$ of IS solution was stirred, $100 \mathrm{ul}$ of acetonitrile was added and extracted in an ultrasonic bath for 3 minutes. The samples were then frozen for 20 minutes at $-70^{\circ} \mathrm{C}$. After thawing, samples were centrifuged at $13,000 \mathrm{rpm}$ at $4{ }^{\circ} \mathrm{C}$ for 25 minutes. The supernatant was carefully decanted into vials for chromatography and analyzed. Test solutions were prepared similarly to standard solutions and solutions QC (Committee for Medicinal Products for Human Use. 2011).

\section{Data analysis}

Results obtained from the HPLC analyses were plotted as concentration-time curves for plasma. Pharmacokinetic analysis was performed using the Microsoft Office Excel 2010 software. The mean area under the curve (AUC) was calculated by the trapezoidal method. The maximum concentration $\left(\mathrm{C}_{\max }\right)$ and the time to reach peak concentration $\left(t_{\max }\right)$ were the observed values. Results are presented as mean values \pm S.D.

\section{RESULTS AND DISCUSSION}

The mean plasma levels of C7070 following a single dose of intragastric and intravenous administration are shown in Fig. 1. The plasma drug concentration data and the PK parameters are presented in Table 1.

We studied the pharmacokinetics of the agent C7070 imidazoline receptor agonist, a potential anti-diabetic drug. Pharmacokinetics and bioavailability of C7070 was studied in blood plasma of Wistar rats after a single intravenous and intragastric administration of $50 \mathrm{mg} / \mathrm{kg}$. C7070 content in the samples was analyzed by HPLC with MS/MS detection.

The results showed that a reduction in the plasma concentration $\mathrm{C} 7070$ blood test animals is rapid and biexponential character. C7070 pharmacokinetic profile in the blood plasma after intravenous and intragastric routes of administration have similar 
Table 1: Plasma pharmacokinetic parameters of C7070 after intravenous and intragastric administration at a dose of $50 \mathrm{mg} / \mathrm{kg}($ mean $\pm \mathrm{S} . \mathrm{D}, n=6)$.

\begin{tabular}{lll}
\hline Parameter & intragastric & intravenous \\
\hline$t_{\max }(\mathrm{min})$ & $170.0 \pm 79.8$ & - \\
$C_{\max }(\mu \mathrm{g} / \mathrm{mL})$ & $17.6 \pm 1.4$ & $33.6 \pm 40.5$ \\
$t_{1 / 2}(\mathrm{~min})$ & $225.2 \pm 12.4$ & $154.1 \pm 5.1$ \\
MRT $(\mathrm{min})$ & $325.0 \pm 17.9$ & $222.3 \pm 7.3$ \\
$\mathrm{AUC}_{0} \_t(\mu \mathrm{g} * \mathrm{~min} / \mathrm{mL})$ & $6592.7 \pm 577.3$ & $37857.7 \pm 3180.1$ \\
Bioavailability $(\%)$ & 18.1 & - \\
\hline
\end{tabular}

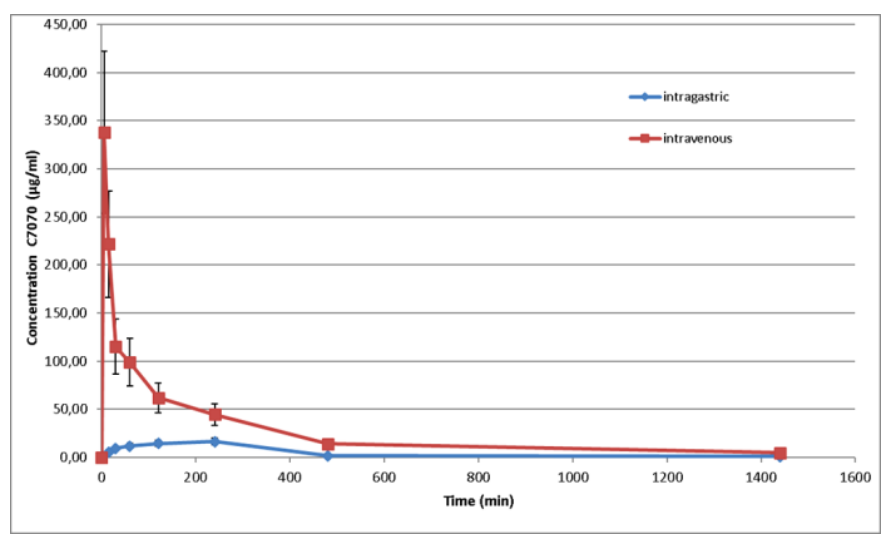

Fig. 1: Average C7070 concentration in plasma as a function of time after intravenous and intragastric administration at a dose of $50 \mathrm{mg} / \mathrm{kg}$ (mean \pm S.D., $n=6)$.

dynamics changes. The mean time of absorption (MAT) was 102.7 minutes. Bioavailability C7070 at intragastric dosing was $18.1 \%$. C7070 is slowly absorbed, $\mathrm{t}_{\max }$ was 170 minutes. However, the concentration of the substance for a long time observed $t_{1 / 2}-225$ minutes in rat plasma. This allows to conclude that the positive properties of $\mathrm{C} 7070$ as a potential anti-diabetic agents. Receiving single dose provides a prolonged therapeutic effect. The first phase (absorption) is smooth in nature, excluding the shock effect. The second phase (distribution) is a fast character, reflecting the rapid distribution of $\mathrm{C} 7070$ in rats. The third phase (elimination) is slow in nature, indicating the length of stay organism rats. C7070 has all the properties of the potential anti-diabetic drug, and will continue to study it.

\section{ACKNOWLEDGEMENT}

The study was supported by grant of the President of the Russian Federation № MD-4711.2015.7.

Conflict of Interests: There are no conflicts of interest.

\section{REFERENCES}

Brigand LL, Virsolvy A, Peyrollier K, Manechez D, Godfroid JJ, et al. Stimulation of insulin Release from the Min6 Cell line by new imidazoline compound, S-21663: evidence for the exitance of a novel imidazoline site in $\beta$-cells. Br J Pharmacol, 1997; 122: 786-791.

Mourtada M, Smith SA, Morgan NG. Effector systems involved in the insulin secretory responses to efaroxan and RX871024 in rat islets of Langerhans. Eur J Pharmacol, 1998; 350: 251-258.

Brigand LL, Virsolvy A, Manechez D, Godfroid JJ, Lematre BG, et al. In vitro mechanism of action on insulin release of S-22068, a new putative antidiabetic compound. Br J Pharmacol, 1999; 128: 1021-1026.

Efanov AM, Zaitsey SV, Mest HJ, Raap A, Appelskog IB, et al. The Novel Imidazoline Compound BL11282 Potentiates Glucose-Induce Insulin Secretion in Pancreatic $\beta$-Cells in the absence of Modulation of KATP Channel Activity. Diabetes, 2001; 50: 797-802.

Olsen HL, Norby PL, Hoy M, Spee P, Thams P, et al. Imidazoline NNC77- 0074 stimulates Ca2+-evoked exocytosis in INS-1E cells by a phospholipase A2 -dependent mechanism. Biochem Biophys Res Commun, 2003; 303: 1148-1151.

Guidance for Industry: Bioanalytical method validation. 2001. U. S. Department of Health and Human Services, Food and Drug Administration, Center for Drug Evolution and Research (CDER), U. S. Government Printing Office, Washington, DC.

Guideline on bioanalytical method validation. 2011. European Medicines Agency -Committee for Medicinal Products for Human Use.

\section{How to cite this article:}

Aleksandr K, Tatyana A, Mikhail P, Mikhail K. Pharmacokinetics of a new imidazoline receptor agonist in rat plasma after intragastric and intravenous administration. J App Pharm Sci, 2017; 7 (03): 006-008. 